meaningfulness between high and low association value nonsense syllables is greater than the corresponding difference between high and low dominance level words. This interpretation seems reasonable since low dominance level words are commonly known nouns whereas low association value nonsense syllables are essentially unfamiliar.

\section{References}

Glaze, J. A. The association value of nonsense syllables. $J$. genet. Psychol., 1928, 35, 255-267.

King, F. J., Reid, I., \& Roberts, D. M. Free recall of intra-list items as a function of serial position, association value and conceptualization. Psychon. Sci, 1966, 4(8), 311-312.

\title{
Developmental level and concept learning: A reply to Te Vault et al
}

\section{by Stanley R. Friedman}

Te Vault et al (1966) have described an experiment which they feel calls into question certain results obtained by previous investigators (Klugh et al, 1964, 1965; Friedman, 1965; Pishkin \& Rosenbluh, 1966) regarding interactions between developmental level and concept learning. Specifically, they question the hypothesis presented by this writer that a demonstrated inversion at the fourth-grade level may be due to the inefficient use of a newly developing mediation process. I shall analyze a number of points raised by Te Vault et al:

1. The author's note (p. 168) "However, it was the fourth grades (9-year olds) which were specifically designated by Friedman as the inverted group, and it is the comparison of fourth-grade children to thirdgraders which is crucial to the hypothesis. "I did not at any point say "9-year olds;" I did say "fourth-grade." There is a difference. (My fourth-graders, in any case, were run in both November and March, and were closer to 10- than 9-year olds.) Klugh et al (1964) also specified grade level; in their 1965 study, age was used, and specified at 9-10 years. Te Vault et al say they used 8- and 9-year old children, specifying neither mean ages nor grades. A reasonable test of the hypothesis would certainly have included a 10-year group, in any case.

2. It has not been claimed that fourth-graders are duller than third-graders, merely that they prematurely form hypotheses when a task lends itself to such a process. However, given a task presenting little opportunity for generation of relatively complex hypotheses, they (fourth-graders) would utilize a simpler associationistic type of responding. Further, they used a correction procedure which would certainly serve to inhibit the formation of complex hypotheses, since each time the $S$ is wrong, he does not have to speculate (i.e., hypothesize) as to the correct response, $E$ informs him of the correct response!

3. They have used a different response measure, i.e., total number of correct responses on the 10 trials. This measure is not necessarily comparable to one using percentage successful Ss at each grade level. Further, it is unclear how they get an error term having 780 df from a 20 cell matrix with a single score per cell (a similar problem with df arises with their post hoc analysis).
4. The fact that no inversion of ranks appeared in the 9-year old group data of the "deviant experimenter" would seem to indicate, if anything, that it was not the experimenter but one or both of the 8-year groups tested by this $\mathrm{E}$ which was deviant. At any rate, why should such an inversion of ranks indicate that anyone was deviant; the fact that in one case an $E$ gets four bright Ss does not guarantee his continuing to be so fortunate in other situations.

5. The fact that the elimination of data of one $E$ produced nonsignificance in all main effects and interactions (other than $\mathrm{E}$ main effect) appears to indicate that the "mediating condition" did not readily lend itself to mediating behavior (what the $\mathrm{E}$ calls the condition and what the $S$ takes it to be do not necessarily coincide) since these Ss did not solve the problem more efficiently than the Ss in the nonmediating condition. This fact alone casts considerable doubt on the validity of their study.

6. Eight experimenters were used in my study (as can be seen in the footnote); all but one of the experimenters participated in the testing of all grade levels; the inversion was found with each experimenter's portion of the total N. Another point is that in my study, each $\mathrm{S}$ continually faced and "interacted" with a wooden display panel, contrasted with the E-S interaction (nonstatistical) inherent in the methodology used by Te Vault et al.

7. And last but certainly not least, the earlier results (Friedman, 1965) have since been replicated (the manuscript presently being completed).

\section{References}

Friedman, S. R. Developmental level and concept learning: Confirmation of an inverse relationship. Psychon. Scr., 1965, 2, 3-4

KIugh, H. E., Colgan, K., \& Ryba, J. A. Developmental level and speed of relational concept formation: A possible inverse rela-tionship. Psychon. Sci., 1964, 1, 89-90

Klugh, H. E., \& Roehl, K. Developmental level and concept learning: Interaction of age and complexity. Psychon. Sci., 1965, 2, 385-386

Pishkin, V., \& Rosenbluh, E. S. Concept identification of auditory dimensions as a function of age and sex. Psychon. Sci., 1966. 4. $165-166$.

Te Vault, R. K., Bailey, Melinda, Cagan, Elizabeth, Dionis, Joan, \& Figelman, Edith. Developmental level and concept learning: A possible artifact. Psychon. Sci., 1966, 5, 167-168. 